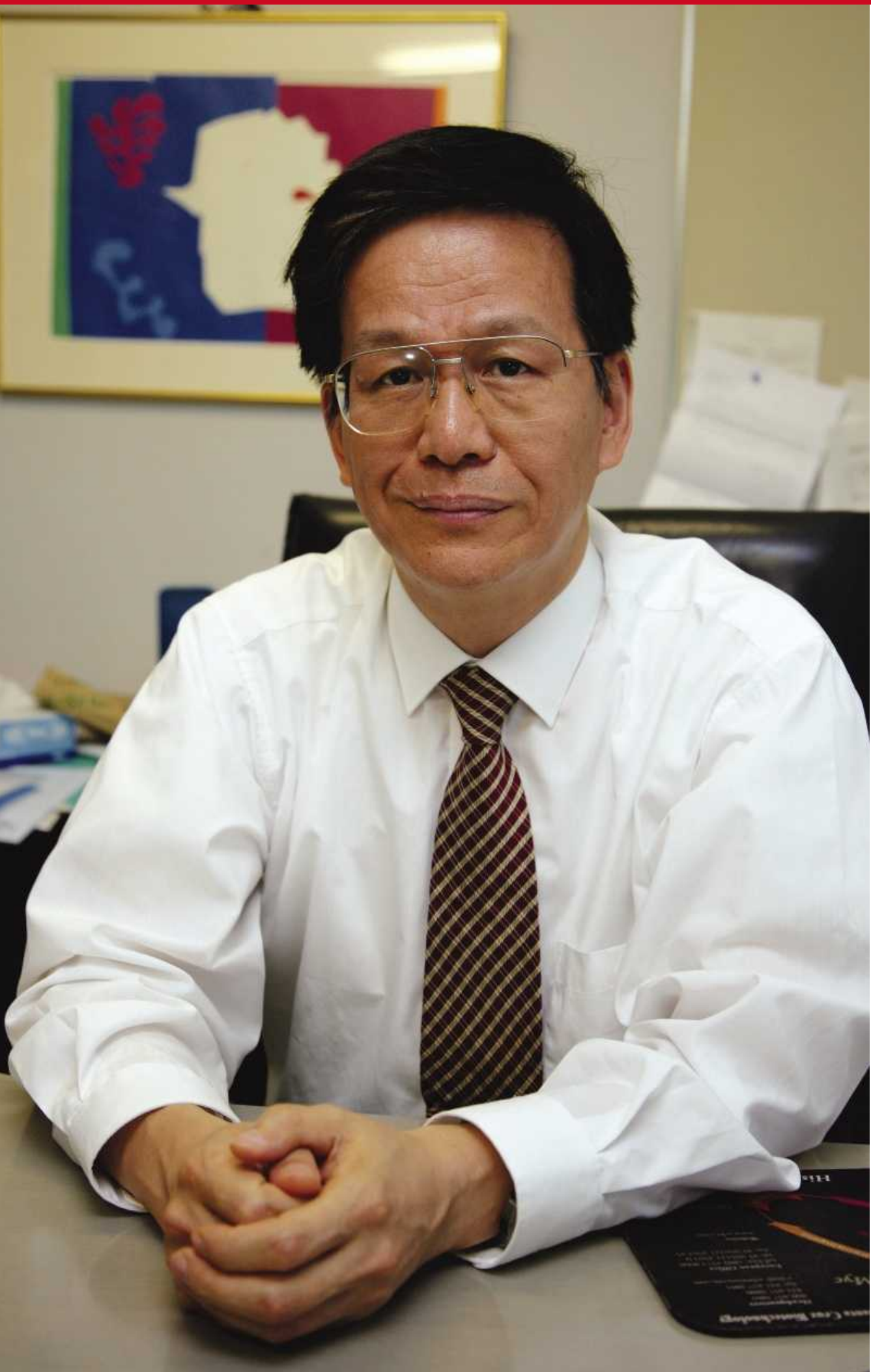

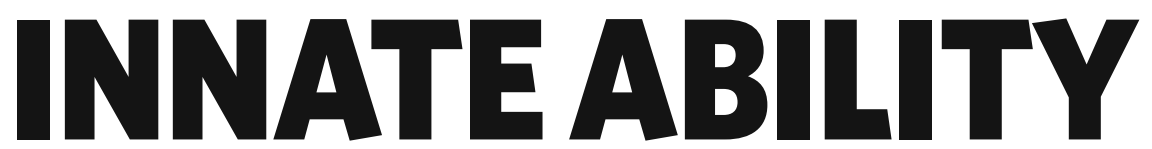

With keen immunological insight and a knockout mouse 'factory', Shizuo Akira leads by quiet example. David Cyranoski visits the world's most-cited scientist as he prepares to run one of Japan's

premier research centres. $\mathrm{n}$ the spring of 2000, Osamu Takeuchi and Hiroaki Hemmi were scanning row upon row of tiny plastic wells filled with a yellow fluid. Finally they found one that had remained clear. The fluid came from cultures in which mouse immune cells that lacked a specific receptor had been challenged with different components of infectious agents - bits of bacterial cell wall, DNA and the like. Yellow signalled that the cells had reacted to the components. Clear meant that they hadn't, revealing the purpose of the missing receptor. The clear well meant that the pair had discovered the function of toll-like receptor 9 (TLR-9), one of a family of proteins that have revolutionized the field of immunology. "I knew we had something right there that no one else in the world knew about," recalls Takeuchi. "I knew it would be a big article."

The article ${ }^{1}$, published in 2000 , would be cited in nearly 2,000 other articles, according to Thomson Scientific's Web of Science. Yet Takeuchi's excitement at their discovery was somewhat lost on his mentor, Osaka University's Shizuo Akira. "He's not that kind of guy," says Takeuchi. "His only response was, 'So what's next?"'

Make no mistake - Akira is passionate about the research. But, he says, "before I get happy, I must be careful. My greatest fear is an incorrect article".

Akira is a man of few words but many publications. For two years running, he has been the world's 'hottest' researcher, according to citation-based rankings by Thomson Scientific in Philadelphia, Pennsylvania. He won the honour with his prolific studies of the innate immune system, creating an army of knockout mice to help deduce the role of the TLRs. Although many around the world have pushed the field forward, the magnitude of Akira's contribution is undeniable. "He owned that field," says Alan Aderem, an immunologist at the Institute for Systems Biology in Seattle, Washington.

Akira's conservative nature and quiet demeanour seem at odds with a researcher who stands at the forefront of one of the fastest moving, most competitive fields in science. He keeps a lab of just 20-25 people. And his lab members say that he does not pressure them or direct experiments from the top down. He doesn't even work late, leaving for home at 5 p.m. sharp. He shares his mice and his knowledge generously, even ahead of publication.

So what has kept this mild-mannered man at the top of the game? His colleagues credit his ability to choose hard-working people and access to financial resources that he parlayed into a 'knockout-mouse factory'. But they also 
recognize his intuition and insight. "If you were digging for oil, he would know where to dig," says Takeuchi, now an associate professor in Akira's lab.

The Japanese government is prospecting. In September, Akira was awarded a 10-year grant to establish a new immunology research centre at Osaka University. One of five projects selected under a new scheme funded by Japan's science ministry, the centre is expected to assume a role of international leadership ${ }^{2}$. Although the scheme's goals are ambitious, Akira's past proves him adaptable.

\section{Back to basics}

In 1980, after two years as a physician, Akira joined the lab of Tadamitsu Kishimoto, an eminent immunologist, at Osaka University. Akira planned to work on T-cell and B-cell interactions, but on his very first day, Kishimoto deposited the 28-year-old in the lab of another scientist, Tasuku Honjo. Honjo worked in an adjoining wing, connected by a bridge between the clinical and basic-research groups. "[Kishimoto] told me I had to learn molecular biology," says Akira. "It was a culture shock. I didn't know what a plasmid or a kilobase pair was." But he accepted his charge. Every day for two years, Akira went to the Kishimoto lab, flipped the wooden name tag to mark his presence, and then headed over the bridge.

The background in molecular biology, and especially genetics, served Akira well, says Kishimoto. "With no computer databases, he sat at his desk and found important sequences. To me, it was just a bunch of letters." Akira seemed to have a knack for the work. "It was like one of those movies about children with special powers," Kishimoto recalls. Aside from a 2-year stint at the University of California, Berkeley, Akira worked at Kishimoto's lab until 1996, getting his name on a major paper every couple of years. The success kept the sometimes tedious work exciting. "It never got depressing," Akira says. But his colleagues definitely noticed his reclusive nature. Kishimoto laughs as he remembers the day a senior professor from a neighbouring lab - the likeable, chatty Tadatsugu Taniguchi — asked him: "Does Akira not like me? He never says hi."

Rather, Akira's work consumed him. In a 1994

\section{MIXED MESSAGES}

Shizuo Akira's knockout mice helped elucidate the function for seven of the ten human toll-like receptors (TLRs). Different bacterial and viral components trigger the TLRs to elicit an immediate innate immune response and trigger the start of acquired immunity. Several TLRs have been targeted in treatments and vaccines.

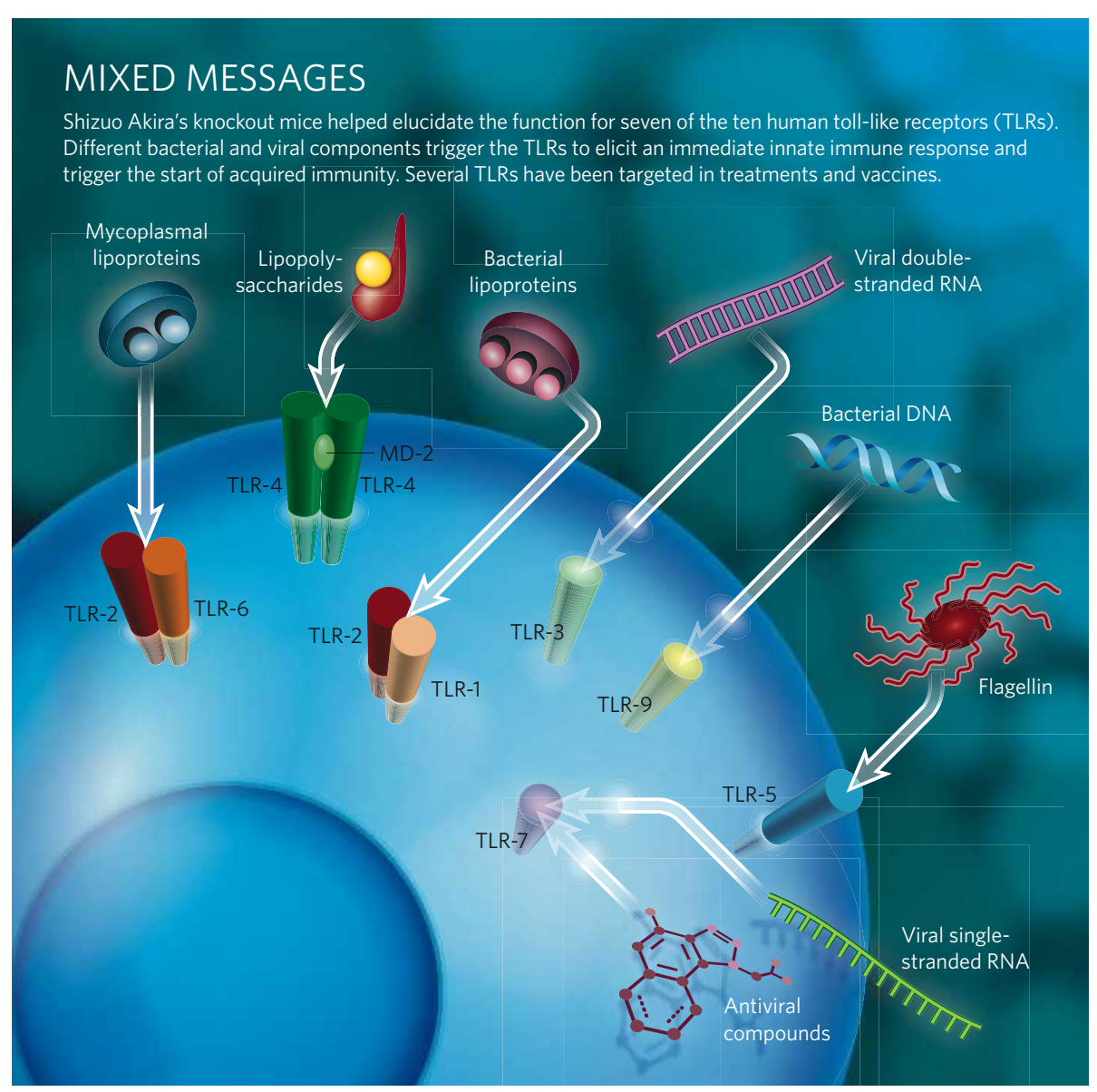

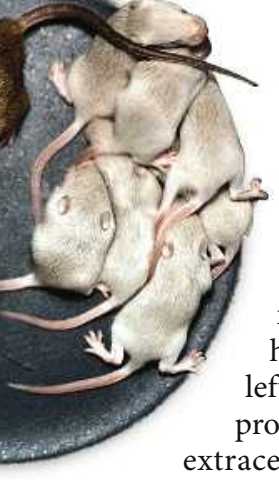

study $^{3}$ on the immunesignalling protein STAT3, he used 6,000 mice in 6 months. By the end of the project, Kishimoto says, the mice dealers were telling him, "There are no mice left in Japan”. STAT family proteins relay signals from ors such as interferon, interleukin, and epidermal growth factor to the nucleus of cells, turning on specific response genes. STAT3 was a key to understanding how each signal gets a specific response, and the work progressed quickly. Akira's publication came out a week after one ${ }^{4}$ from a lab at Rockefeller University in New York, run by James Darnell. "I didn't even know we were competing until Kishimoto heard about their work at a conference," Akira says. On the back of his strong publication record, Akira became an independent researcher, first at Hyogo College of Medicine in 1996, then back at Osaka University in 1999, just when the field of innate immunity was starting to take off.

For decades, researchers had focused their attention on acquired immunity, the domain of T-cells and B-cells that rearrange their DNA to target and destroy invaders. This is the system that gives vertebrates the ability to remember infections and to become immunized against them. Innate immunity, on the other hand, is a first line of defence. It had been seen as a ham-fisted relic of evolution, indiscriminately engulfing and digesting incoming microorganisms, mounting a generalized, sometimes powerful inflammatory response, and relaying information about the invading bacterium or virus to the more-sophisticated acquired response.

\section{Toll gates}

But innate immunity is much smarter than it had let on, and its genius lies in the TLRs. Toll, for which the TLRs were named, was originally identified as a gene involved in the embryonic development of Drosophila. Experiments by Jules Hoffmann at the Institute of Molecular and Cellular Biology in Strasbourg, France, in 1996 showed that the gene also helped to protect the flies against fungal infection ${ }^{5}$. In 1997, a human homologue, a TLR, was found to have a function in immunity ${ }^{6}$. And in 1998, Bruce Beutler, a geneticist at the Scripps Research Institute in La Jolla, California, used genetic-mapping techniques to identify a mutation in the Tlr4 gene as being responsible for the failure of some strains of mice to produce the often fatal 


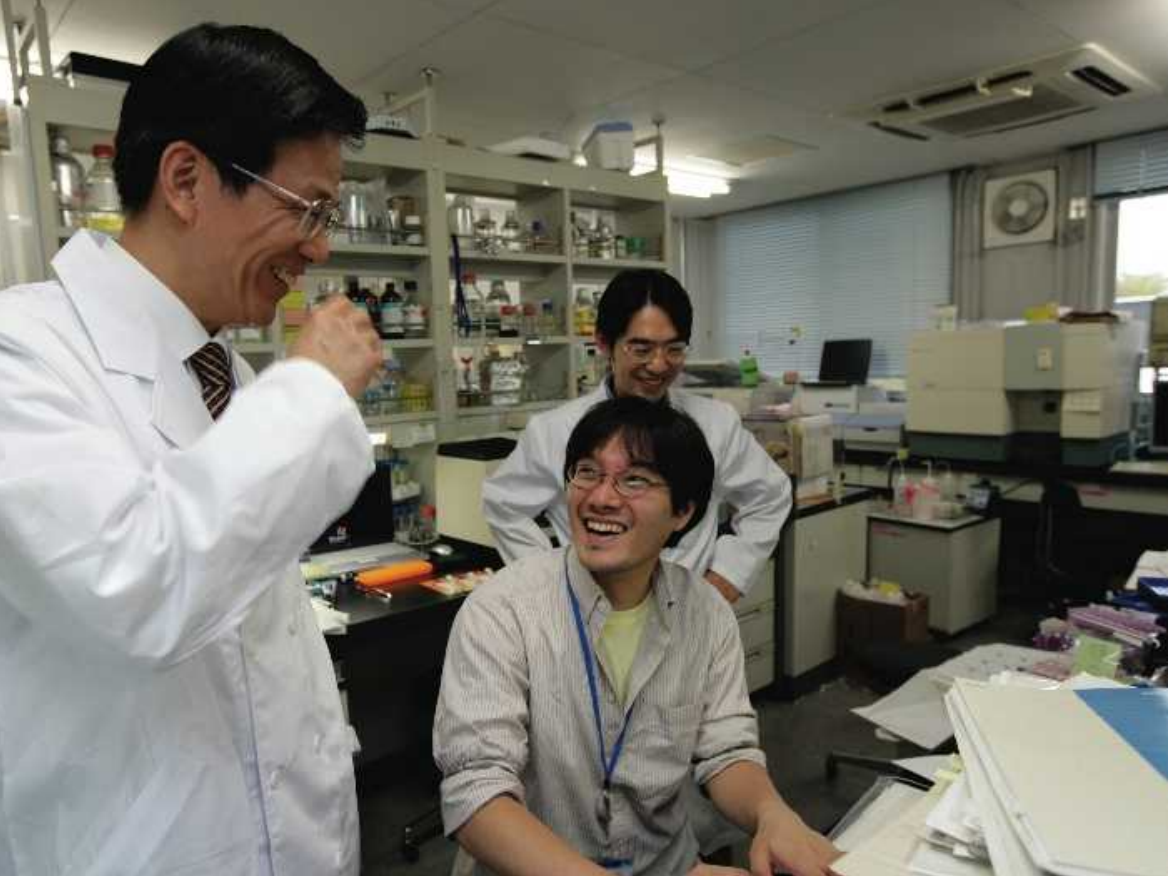

Shizuo Akira (left) shares a laugh with his colleagues Yutaro Kumagai (centre) and Osamu Takeuchi.

toxic-shock reaction after they were infected with Gram-negative bacteria $^{7}$. Without the protein to recognize and respond to the presence of the bacteria, the mice didn't have the powerful reaction that would kill them. Coincidentally, as Beutler's article appeared, Akira was preparing his own manuscript showing that purposely knocking out $T l r-4$ produced mice just like Beutler's ${ }^{8}$.

Genetic data showed that mice had 12 TLR genes, 9 of which were very similar to human genes. With expertise in the field and a head start on some of the other knockout mice, Akira helped to pin down the function of seven of these TLRs in short order, showing what kind of invaders they recognized and in some cases how they exerted their effects. The TLRs have a surprising ability to recognize patterns specific to different components of antigens: lipopolysaccharides - huge fat and carbohydrate residues on the surface of Gram-negative bacteria - activate TLR-4, but other TLRs respond to lipoproteins, specific DNA patterns, double-stranded RNA or bacterial flagellin (see graphic). "We thought they might be redundant, but they were all different," says Akira, who calls his discovery, with Takeuchi and Hemmi, of the function of TLR-9, his proudest. Among the long strings of As, Ts, Cs, and Gs in DNA, some parts have dense concentrations of $\mathrm{C}$ and $\mathrm{G}$. In mammalian genomes these bases are usually methylated. In bacteria they are not. TLR-9 identifies unmethylated DNA. Such subtle specificity from a seemingly brutish innate response wasn't expected. "People couldn't believe it," he said.

Akira's achievements have gotten his name on some 600 articles. But many of those roughly half, says Akira off the top of his head was to supply the mouse. The arrangement has certainly helped him become the hottest name in science. But his colleagues add him willingly. According to Aderem, the convention is to credit a researcher who shares a mouse with authorship of one or two articles resulting from work with that mouse. "In his case, they keep putting him on," he says.

\section{Shared success}

And there may be reasons for that. Akira's generosity surprised Aderem when he asked for a mouse lacking lipocalin-2, which proved to be a key component in the immune response to bacterial infection" "He just ing that it's extremely rare for people to share their resources before they've gone through them completely. "Absent his mice, the field would not have moved forward," he adds.

Akira's 'factory' has 100-200 knockout mice, Takeuchi estimates. Graduate students each make some 5-10 knockouts, which is an impressive amount. The process, for which the 2007 Nobel Prize in Physiology or Medicine was awarded, requires a series of trial-anderror procedures that can take up to a year and a half per strain to complete. And in the end, the knockout might not even have a clear effect. "If there's no phenotype, it's useless," says Himanshu Kumar, a fourth-year graduate student. Is it fun? "No, not at all. But it's exciting if you're getting good results."

Those in the lab appreciate Akira's advice, but he doesn't push them. "He doesn't have to. The field itself is competitive," says Coban Cevayir, a Turkish postdoctoral student who has worked with Akira for four years.

Akira has now moved beyond TLRs to
- are collaborations in which his main role gave it to me," he says, add- address broader aspects of signalling mechanisms within innate immunity. The broader focus set the stage for a collaboration he began last August with Beutler and Hoffmann. The team has a 5-year grant from the US National Institutes of Health to look at host defence against viral infection. "His work is bringing a renaissance to immunology," says Beutler.

And then there's the World Premier International Research Center grant from Japan's science ministry. The grant will provide billions of yen (tens of millions of dollars) to set up new institutions, starting with $¥ 700$ million for to build the Immunology Frontier Research Center, a ten-story building near Akira's lab. The centre's aim is ambitious: "To unveil the whole picture of the dynamic immune system by employing a variety of imaging techniques to visualize the immune cells within live animals." Akira says that previous studies have shown how different molecules function, but not much about how important their response is when a bacteria or virus actually enters the cell. The imaging techniques will show the "spatial and temporal relationships" so "we can see the extent to which different cells contribute to the immune response", he says. "We want to see the immune system as a whole."

The centre's principal investigators will include nine immunologists from Osaka University, including Kishimoto, three others from Japan, including Kyoto University's Shimon Sakaguchi who propelled the field of regulatory T-cells forward, and Fritz Melchers of the Max-Planck Institute for Infection Biology in Berlin, Germany. It will also have a large imaging component, including Osaka University's single-molecule imaging pioneer Toshio Yanagida ${ }^{10}$ and six collaborating labs in the United States.

Holding this high-calibre, multi-disciplinary, international project together will be a management challenge for the quiet doyen of immunology. The past couple years of fame and media attention have made Akira much more open and outgoing, Kishimoto observes. But he will probably still keep his comments to a minimum and let his science do the talking. David Cyranoski is Nature's Asia-Pacific correspondent.

\footnotetext{
. Hemmi, H. et al. Nature 408, 740-745 (2000).

2. Nature 447, 362-363 (2007)

3. Akira, S. et al. Cell 77, 63-71 (1994)

4. Zhong, Z., Wen, Z. \& Darnell, J. E. Jr Science 264, 95-98 (1994)

5. Lemaitre, B., Nicolas, E., Michaut, L., Reichhart. J. M. \& Hoffmann, J. A. Cell 86, 973-983 (1996).

6. Medzhitov, R., Preston-Hurlburt, P. \& Janeway, C. A. Nature 388, 394-397 (1997).

7. Poltorak, A. et al Science 282, 2085-2088 (1998)

8. Hoshino, K. et al. J. Immunol. 162, 3749-3752 (1999).

9. Flo, T. H. et al. Nature 432, 917-921 (2004).

10. Nature $408,764-766$ (2000)
}

\section{$\sum_{\substack{i \\ ⿱ 亠 乂}}^{\mathbb{4}}$}

